\title{
建筑外墙保温节能技术在建筑施工中应用
}

\author{
吴天成 崔智翔 \\ 中建二局第四建筑工程有限公司 \\ DOI:10.32629/btr.v3i5.3120
}

[摘要] 在新时代背景下,我国经济水平逐步提高,建筑施工得到了人们普遍的关注。现如今我国社会的环保意识越来越强,建筑工程同样需 要顺应时代的要求, 除了需要积极应用绿色节能技术之外,还要确保用户居住的舒适度不会受到任何影响。为此, 施工人员便需要在外墙施工 的时候,积极应用保温节能技术, 以此提升施工的整体效果。基于此,本文对建筑外墙保温节能技术在建筑施工中应用进行研究,作出以下讨论 仅供参考。

[关键词]建筑外墙；保温节能技术；建筑施工；应用

一般在建筑外墙施工中, 除了保障其美观性, 也需要考虑其价值属 性, 利用保温材料与保温施工能够提高建筑外墙的保温性能, 这就减少 了建筑物室内保温能源的利用, 间接达到的节能价值。所以在建筑外墙 施工中, 建筑物的保温节能施工技术还需要不断优化, 提高外墙外保温 节能性能, 从而提高建筑物的价值属性, 为建筑外墙施工提供更多创新 优势。

\section{1 建筑外墙外保温节能施工的优势}

建筑外墙外保温节能施工技术不仅能够起到很好的保温与节能价值, 其对于建筑物使用寿命也有较好的延长作用, 由于外保温节能施工技术会 在建筑外墙涂抹保护层, 所以能够阻挡对建筑物有害的紫外线、气体等, 降低建筑物受到这些因素影响的可能性, 很好地起到了建筑物的保护作用, 且外保温节能施工技术形成的保护层能够抵御自然气候环境如雨水等对 墙体的侵蚀, 减少了建筑物渗漏问题, 所以对建筑外墙进行外保温节能施 工还能够很好地保护建筑物, 延长其使用寿命。最重要的是, 在建筑外墙外 保温节能施工后, 其能够形成保温层, 不需要墙体增加额外隔热气层也能 够减少建筑物内蒸汽的渗透, 很好地提高了建筑墙体的热工性能, 其能够 维持建筑物内的室温, 减少热气流失, 也减少了采暖设备的应用, 能源消耗 降低, 真正达到节能效果。并且在外保温墙施工后, 建筑物内部的温度差会 较小一些, 为居住者提供舒适的居住环境, 在室温调节与改善上具有积极 意义。

\section{2 建筑外墙保温节能技术在建筑施工中应用}

2. 1 建筑物基墙的处理

为了可以有效地发挥出外墙保温技术的作用, 所以, 在进行施工前, 需
要对施工的墙体进行科学的处理, 保证墙体的干净整洁; 在对墙体进行处 理时, 需要严格地按照相关的施工要求去完成, 否则, 就会出现无法预估的 影响, 在进行施工时, 如果对墙体的水分使用不合理就会出现一系列的问 题, 水分过多, 就会对墙体造成破坏。所以, 在进行施工时, 相关的技术人员 一定要控制好水分。

2.2 外挂式的保温技术应用

建筑外墙时使用外挂式保温技术中主要应用岩棉、玻璃棉毡、聚苯板 等, 而聚苯板以其较低成本和较好的自身物理特性, 而受到了广泛的欢迎, 并在世界各地的建筑业中得到了广泛应用。应用外挂式技术主要用粘接砂 浆、固定件等把保温的材料贴在或是挂在建筑的外墙上, 然后将一些抗裂 的砂浆涂抹上去, 压入到玻璃纤维的网格布中, 然后在保温层的上面再进 行装饰面的装饰。

2. 3 聚苯颗粒保温技术的应用

在对建筑物做保温处理时, 选择胶粉聚苯颗粒浆料作为建筑复合墙体 材料, 在应用中主要应关注墙体底层位置的施工。(1) 在实际施工之前, 首 先应当做好建筑基层墙体的清洁工作, 将墙体表面存在的污垢、浮灰、油 污等去除, 在保证墙体干净、清洁之后在进行涂抹施工。(2) 科学调配水泥 砂浆的比例, 使工程项目能够均匀混合交及混合。(3) 通过冲筋施工控制筋 宽和筋厚, 通常筋宽应控制在 $5-7 \mathrm{~cm}$ 左右, 厚度与保温层相当。(4) 在以上 施工步骤完成之后, 等待 $2 \mathrm{~h}$ 左右, 然后将准备好的聚苯颗粒保温材料涂抹 于墙体之上。通常第一遍涂抹时应尽量控制厚度, 且禁止出现来回拉抹的 情况发生, 在对阴角位置处理时宜采用从外向内打鱼鳞状底粘的涂抹方 法。当第一遍涂抹材料充分干燥之后, 再对其做第二遍涂抹, 此时应注意控

太暗或者太强。在亮度选择方面, 为了使驾驶员和行人有足够的反应时间 和操作时间避开障碍物, 必须保证灯光亮度能使驾驶员和行人在一定范围 内看清障碍物。通过使用各种科学技术, 合理布局, 能够保证人们出行安全, 减少交通安全事故出现。

\section{4 结束语}

总而言之, 随着社会经济快速发展以及科技水平逐渐提高, 让人们实 际生活质量发生某种程度改变, 人们对自身生活环境有着较高要求, 这直 接影响到我国城市道路的发展。在城市道路设计中, 设计人员应按照以人 为本设计要求, 科学设计, 改善城市道路环境, 提高城市道路的适用性, 给 人们出行提供良好的环境, 保证人们出行安全。

[参考文献]

[1]田宗. 城市道路设计存在的问题及改进措施 [J]. 四川水 泥,2015,(02):176+25.

[2]徐洋.城市道路设计存在的问题及改进措施 [J]. 全面腐蚀控 制,2020,34(03):69-70.

[3]党顺意.论城市道路设计中应注意的问题[J].民营科技,2017,(12):87.

[4]金尧.探究 “智慧城市” 背景下的城市道路设计创新[J].低碳世 界,2018,(09):250-251.

[5]卢小华.分析城市道路设计中生态理念技术运用[J].黑龙江交通科 技,2015,38(05):33.

[6]李因宜.现代城市道路设计的基本方法与思路探讨 [J].中国西部科 技,2009,8(12):83-84.

[7]周小群,朱德宏. 以人为本的城市道路设计探讨 [ J]. 科技信 息,2007,(07):216+121.

[8] 于科峰,赵淑丽,邹清斐.城市道路设计存在的问题和改进建议 [J]. 城市道桥与防洪,2017,(10):37-39+9. 
制墙体的平整度。在建筑工程中应用该项保温技术, 不仅能够有效提升墙 体的保温性能, 而且能够在一定程度上降低施工能耗, 对环境综合治理有 着较好的效果。

2. 喷涂式保温技术应用

喷涂式保温技术一般是在建筑外墙的外侧处喷涂保温材料, 保温材料 在沉淀一定的时间后成为保温层, 以此来达到保温节能的效果。一般来说, 喷涂式保温技术使用最多的材料为聚氨酯硬质泡沫塑料材料, 因为其特殊 的化学性质, 这种材料在耐腐蚀性方面很有优势, 而且其吸水性和导热性 较差, 在一定程度上可以促进材料和建筑外墙的连接, 以此来保证其使用 年限。

\section{5聚苯板薄抹灰技术应用}

聚苯板薄抹灰技术也是当前建筑物中应用较为广泛的技术, 但在对该 项技术进行实际应用时, 为了能够建筑物具备较高的保温性能, 还需要对 其中阳角、门窗以及檐口等部位做特殊性处理。通常在施工中应采用挂垂 线或者使用经纬仪来确定阳角基准线, 并对施工水平度做严格的控制。粘 贴施工时应当尽量采用整块板材, 以此能够有效降低拼接时产生的缝隙, 从而提升外墙保温施工质量。另外, 在实际施工操作中, 由于聚苯板是粘贴 于墙面之上, 为保证其后期具备较高的稳固性, 具备较为长久的使用寿命, 对所采用的粘结剂要求往往较高。

\section{6 保温板与砂浆的黏结技术应用}

这项技术的使用对于墙体的质量起着至关重要的作用, 但是这项技术 的施工难度大, 要求高。保温板顾名思义就是起到保温的作用, 所以, 在进 行施工中粘贴保温板就是一项重要的工作, 要严格的控制粘贴的质量。在 进行外墙的施工中, 一般都是采用条点法, 就是将保温板和砂浆进行有效 的粘贴, 保证好粘贴的质量。对于, 粘贴的环境也有着严格的要求, 确保不 出现空隙以及裂缝, 以此达到对墙体的保温作用。

\section{3 建筑外墙保温节能技术应用注意事项}

3. 1 选择合理的保温节能材料

保温材料在选择时除了自身保温效果的优势, 还要注意能够有效的实
现节能降耗, 并且要对人们的健康有利, 这才是选择保温节能材料的最终 目的。在实际的工程施工中, 应用比较广泛的材料有酚酫树脂发泡材料, 已经受到了广泛的关注。在保温施工过程中, 一定要做好保温实验, 结合工 程的实际情况及现场技术要求, 分析可能产生的各种危害, 是否能能够达 到环保的标准, 在进行选择合适的保温材料, 选择的原则是既能实现保温, 又能实现节能, 还要能满足人类健康的需求, 缺一不可, 做好施工中充分的 达到良好的施工效果。

3.2 做好保温砂浆涂抹方面的处理

墙体在应用保温材料前, 相关人员需要将墙体浸润, 以此来依据设计 人员设计的厚度来涂抹水泥砂浆, 在此基础上, 必须要等到水泥砂浆凝固 之后才可喷涂保温材料。不仅如此, 施工人员在施工过程中必须要严格遵 循施工工序, 依据施工规范进行施工, 以此来保证施工工作的质量和人身 安全。

\section{4 结语}

随着建筑行业和科学技术的迅速发展, 绿色建筑的概念也渐渐地开始 被人们接受, 为了满足人们对建筑的要求, 顺应社会发展的趋势, 建筑工程 外墙保温节能技术得到了广泛应用, 并且越来越受到人们的喜爱并且取得 了一定的成绩, 为建筑行业实现可持续发展奠定了坚实的基础。通过它的 合理应用能打造节能建筑物, 还能使建筑施工降低成本、节能, 提高经济效 益, 又能增强建筑物的舒适度。

\section{[参考文献]}

[1]李文军.建筑外墙保温节能技术在建筑施工中应用[J].绿色环保建 材,2020(04):32+34

[2]刘翠芹,韩晓龙.建筑外墙施工中外保温节能施工技术的应用研讨 [J].中国标准化,2019(16):55-56.

[3]韩乐.外墙保温技术在建筑工程施工中的应用分析[J].建材与装 饰,2020(09):30-31.

[4]代彩勇.保温节能施工技术在建筑外墙施工中的应用分析[J].居 舍,2019(23):45. 